\title{
O CORREIO COMO BRAÇO LOGÍSTICO DO ESTADO: A EXECUÇÃO DE POLÍTICAS PÚBLICAS POR MEIO DA REDE DE AGÊNCIAS POSTAIS NO TERRITÓRIO BRASILEIRO
}

\author{
Igor Venceslau \\ USP - Universidade de São Paulo
}

\section{Resumo}

Este trabalho tem o objetivo de revelar como a capilaridade de agências postais no território brasileiro e o serviço de logística dos Correios se tornaram fundamentais para a execução de politicas públicas. Sustenta-se a ideia do correio como um braço logístico do Estado, atualizando a sua relevância como um serviço público. A partir da instalação de fixos geográficos em todos os municípios, os Correios agem como um "braço logístico" do Estado. Dentre essas políticas públicas, destacam-se: o planejamento e ordenamento territorial urbano; o Banco Postal; a distribuição de vacinas; a distribuição de livros didáticos e logística dos materiais dos exames nacionais de educação; a emissão de documentos; a distribuição de donativos. Por fim, evocou-se a ideia de modelo cívico do território para problematizar a relação entre Estado, logística e cidadania na contemporaneidade.

Palavras-chave: (Uso do) Território; Logística; Estado.

\begin{abstract}
Resumen
Este trabajo tiene por objetivo revelar como la capilaridad de las oficinas postales en el territorio brasileño y el servicio de logísitca de los Correios se han convertido en fundamentales para la execución de políticas publicas. Se sustenta la idea del correo como brazo logistico del Estado, actualizando su relevancia como un servicio público. Partiendo de la instalacíon de los fijos geográficos en todas las municipalidades, los correos actuan como un "brazo logístico" del Estado. Se han destacado en el ambito de estas políticas públicas la planificacíon y el ordenamiento territorial urbano; el Banco Postal; la distribucion de vacunas; la distribución de libros didacticos y la logísitca de los materiales los examenes nacionales de la educación; la emisión de documentos; distribución de donaciones. Al fin, se ha evocado la idea de modelo civico del territorio para la problematizacion de la relación entre Estado, logística y ciudadania en la contemporandeidad.
\end{abstract}

Palabras clave: (Uso del) Territorio, Logística; Estado.

\section{Introdução}

volume de cartas e encomendas vem apresentando um crescimento vertiginoso nos últimos anos, contrariando as previsões sobre a perda de importância do correio com o advento da Internet. De fato, o chamado mundo virtual acabou por aumentar a demanda dos Correios para a realização de entregas das compras no comércio eletrônico. No Brasil, os serviços postais passaram por profundas transformações nas últimas décadas, com des- 
taque para a criação do Serviço de Encomenda Expressa (SEDEX) pelos Correios na década de 1980 e sua ampliação nas décadas posteriores, emblemático da aceleração na circulação de mensagens e mercadorias e do uso intensivo das tecnologias de informação no período atual.

Mas a história do correio brasileiro é bastante anterior e remonta ao século XVII, com a instauração do correio-mor da colônia. Concomitantemente às mudanças político-administrativas e técnicas no serviço postal, houve gradual ampliação das localidades atendidas e a consequente integração territorial assim possibilitada. No início do século XX, o serviço passou ao Departamento de Correios e Telégrafos (DCT), transformado em 1969 em Empresa Brasileira de Correios e Telégrafos (ECT ou Correios). A partir de então, uma série de dispositivos normativos legais em âmbito nacional (especialmente a Lei Postal n6538/1978 e a Constituição de 1988) e internacional (acordos no seio da União Postal Universal, órgão das Nações Unidas), levaram à instituição do monopólio postal da União e à universalização do serviço postal para todos os municípios, características marcantes da atuação dos Correios no território brasileiro até os dias atuais.

Este artigo tem origem em pesquisa de mestrado já concluída, cuja investigação contemplou a importância atual do correio para a integração do território brasileiro (VENCESLAU, 2017). Neste artigo, apresentamos uma pequena parte da discussão oriunda dos resultados daquela pesquisa, com o objetivo de revelar e discutir algumas políticas públicas executadas pelo Estado brasileiro por meio da rede de agências dos Correios. Para tanto, foram levantados dados quanti e qualitativos por meio de publicações oficiais da Empresa Brasileira de Correios e Telégrafos ECT, além de entrevistas realizadas em trabalhos de campo nas cidades de Brasília e São Paulo, cujos resultados foram discutidos com fontes bibliográficas de geógrafos e outros cientistas sociais.

Perseguimos um caminho de método que considera a tríade Estado-território-mercado como explicativa das realidades nacionais contemporâneas (ARROYO, 2004). Quanto ao território, categoria cara à ciência geográfica, estamos considerando-o associado à sua dinâmica social. Conforme Gottmann ([1975] 2012, p.523), o território pode ser considerado como "conexão ideal entre espaço e política", mas também como expressão da relação entre tempo e política, pois historicamente se modificaram as formas de poder político e o próprio território. O território é usado por diversos atores, hegemônicos ou não, para finalidades as mais variadas. Como abrigo, o território conforma um uso cotidiano pelas populações dos lugares; como recurso, ele é usado para outros fins, como a obtenção do lucro e a reprodução da mercadoria. Concordando com Santos e Silveira ([2001] 2011, p.15), afirmamos que "é o uso do território, e não o território em si mesmo, que faz dele objeto da análise social". Território e rede não são excludentes, pois não há forma reticular fora do espaço geográfico. A rede é tomada aqui como elemento constitutivo do território e seu papel fundamental para a ação de agentes diversos (RAFFESTIN, 1993; SANTOS, [1996] 2012). A logística, como versão atualizada da circulação corporativa (CASTILLO, 2011), fomenta a constituição e proliferação de redes no território, podendo ser considerada "a nova racionalidade capaz de explicar a simultaneidade da desordem/ordem, da globalização/fragmentação" (BECKER, 2010, p.290).

A discussão a seguir está estruturada em três partes, além das considerações finais. $\mathrm{Na}$ primeira, apresentamos brevemente as políticas que se valeram da rede postal brasileira para a sua execução, principalmente aquelas correspondentes às últimas duas décadas. Em seguida, enveredamos por uma discussão a respeito do serviço postal e seu sentido para a cidadania, num 
país com grades desigualdades sociais e regionais como o Brasil. Na terceira parte, por fim, questionamos a pertinência de pensar uma logística em benefício dos lugares.

\section{Correios e políticas públicas}

A logística dos Correios no Brasil está amparada numa rede de fixos para postagens, triagem/transporte e distribuição de objetos postais, cuja máxima expressão de capilaridade é a presença de agências próprias em todos os municípios brasileiros, que somam quase 7 mil unidades de postagem e mais 9.196 unidades de distribuição. Todavia, como o território brasileiro é marcado por profundas desigualdades (intra e inter) regionais e por desigual disposição de infraestrutura dentre outras condições gerais de circulação, os prazos de entrega são bastante diferenciados, colocando um desafio maior para a logística e revelando a importância da componente territorial.

As desiguais condições de circulação no território brasileiro são desafios à logística dos Correios, que acaba internalizando-as sob a forma de diferentes prazos de entrega. A análise das cidades com prazo de entrega de um dia útil é ilustrativa dos pontos do território nacional dotados de maior fluidez (Mapa 1). Do total de 160 municípios onde é possível garantir esse prazo rápido, 122 deles correspondem às capitais dos estados e suas respectivas regiões metropolitanas. Esse dado demonstra, por um lado, o caráter extremamente metropolitano e seletivo da fluidez territorial no Brasil e, por outro, o resultado da política dos Correios de incluir todas as capitais em sua rede de transporte aéreo de carga, independentemente da demanda de mercado. Assim, nos estados do Acre, Alagoas, Amazonas, Amapá, Maranhão, Piauí, Roraima, Rondônia e Tocantins, todos eles das regiões Norte e Nordeste, a maioria com desenvolvimento econômico menos expressivo no conjunto da federação, a máxima fluidez alcança somente o município da capital. Em estados como Pernambuco, Rio Grande do Norte, Ceará, Goiás, Espírito Santo, entre outros, municípios da região metropolitana da capital, como Olinda-PE e Vila Velha-ES também estão incluídos nas áreas de prazo mais rápido. Como tendência geral, há o reforço às mesmas regiões que ofereciam as melhores condições para a difusão dos serviços postais no passado, demonstrando a relevância da formação socioespacial.

Fora das capitais e suas respectivas regiões metropolitanas, os pontos atingidos por fluxos de maior velocidade são bastante seletivos. Apenas seis estados oferecem condições de fluidez que permitem a entrega no dia seguinte em cidades do interior. Somente no estado de São Paulo é possível encontrar as condições de fluidez territorial que permitem aos fluxos postais alcançarem diferentes lugares com a mesma velocidade. Excluídas as capitais estaduais e suas regiões metropolitanas, três em cada quatro municípios brasileiros onde a entrega dos Correios é realizada no dia seguinte à postagem estão localizados no estado de São Paulo.

As áreas de maior viscosidade no território brasileiro, ou seja, aquelas áreas dotadas de menores condições de fluidez e consequentemente onde os prazos de entrega são os mais lentos, são formadas por municípios da região Norte, em sua maioria, e alguns da região Nordeste e do Mato Grosso. 


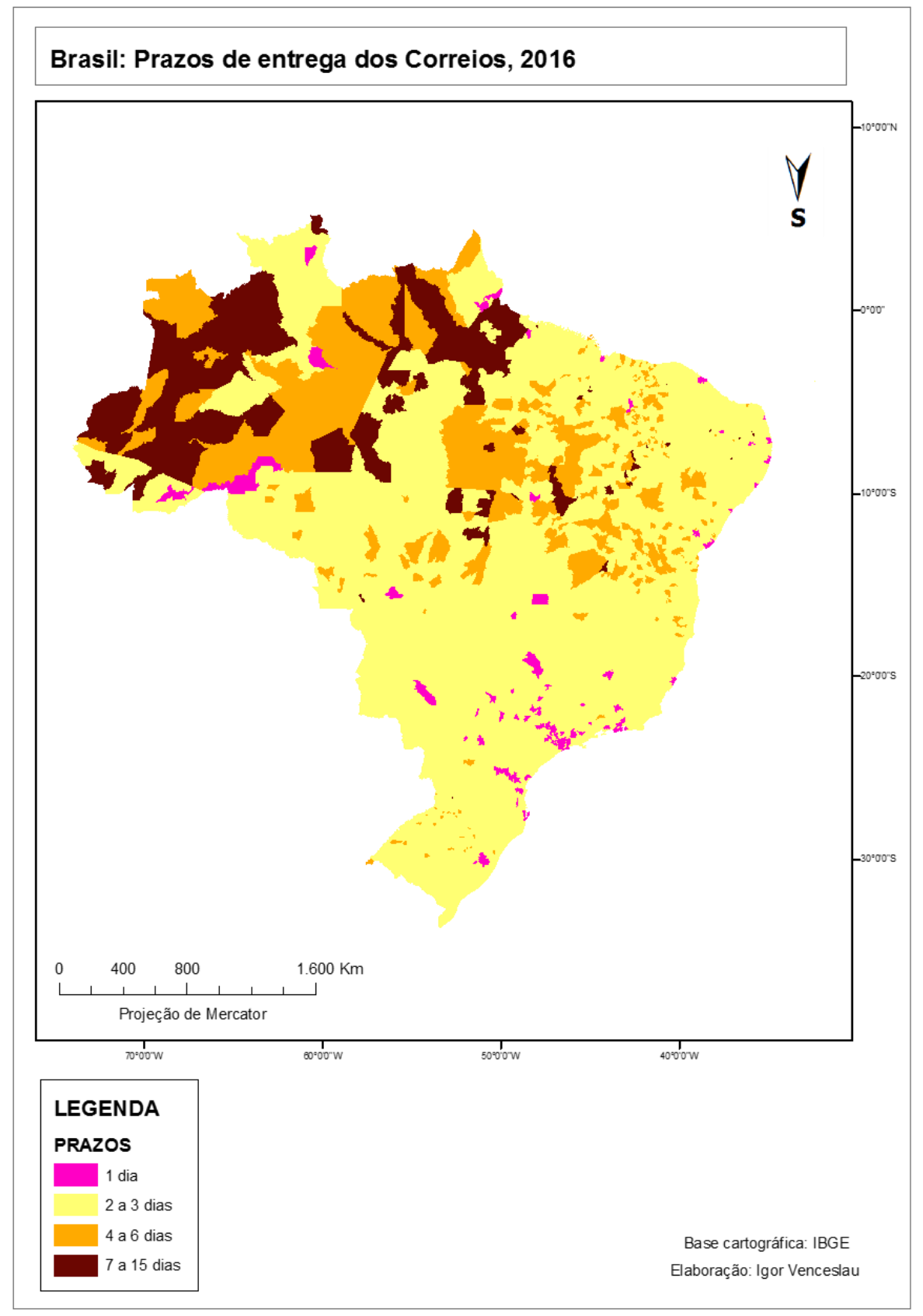

Mapa 1. Brasil: prazos de entrega dos Correios, 2016. Localidade-base de referência oficial para o cálculo: cidade de São Paulo. Serviço postal de referência: SEDEX. Fonte: Venceslau, 2017.

Se, por um lado, a logística postal não pode fugir dos constrangimentos que impõe o território brasileiro com as suas desigualdades historicamente constituídas, por outro lado, ao integrar todos os municípios numa mesma rede de circulação, o correio público acaba por ser um importante agente de integração territorial e de superação dessas mesmas desigualdades.

Além das tradicionais atividades relacionadas ao serviço postal e telegráfico, as agências dos Correios cumprem uma função importante como fixos geográficos a partir dos quais se torna 
possível uma gama de outras ações. De acordo com Romulo Valle ${ }^{1}$, os Correios como única instituição presente em todos os municípios brasileiros faz com que sua capilaridade seja "um elemento diferencial quando se pensa na implementação de políticas públicas". Nesse sentido, a execução dessas políticas encontra na rede constituída pelos Correios um elemento da materialidade do território que permite a sua concretização. O trabalho de Pereira (2007) revelou que isso não se deve apenas ao dado da topologia da empresa (técnico), mas reside no fato mesmo de sua natureza como empresa estatal (político) e que unidas essas condições resultam em benefícios para os lugares:

O fato de os Correios serem, simultaneamente, uma empresa com ações dispersas e também uma empresa estatal, permite que parte considerável de sua atuação social consista na utilização da rede logística do serviço postal no auxílio da implementação de políticas públicas (PEREIRA, 2007, p.145).

Desta maneira, o correio público, para além de suas funções tradicionais, cumpre um papel importante como um "braço" logístico do Estado, como também apontado por Mattelart (1994) para outros países. No caso brasileiro, a dimensão territorial e as desigualdades regionais sinalizam para o reforço dessa importância do correio, que ultrapassa em muito a simples responsabilidade social. Portanto, quais seriam as políticas públicas nas quais a participação dos Correios é condição sine qua non para a sua execução? E de que maneira a atuação dos Correios se constitui no fomento à criação de solidariedades no território?

Em primeiro lugar, os Correios participam ativamente da elaboração de um dos ingredientes básicos da cidadania: a criação de endereços. É a empresa postal pública que, juntamente com as prefeituras municipais, formaliza os logradouros, concedendo o número respectivo de CEP e permitindo aos moradores utilizarem um endereço formal. A criação do endereço pode ser entendida como a outorga da cidadania, pois só a partir de então podem ser solicitados serviços básicos de água, saneamento e eletricidade, abertura de conta bancária, cadastramento em programas sociais, entre outros. Essa atribuição dos Correios ultrapassa suas funções básicas de provedor dos serviços postais para alcançar um patamar de agente ativo na organização e regulação do espaço.

Outro elemento da cidadania é, no Brasil, a produção do documento denominado Cadastro de Pessoa Física (CPF). Inicialmente o documento era emitido somente nas agências da Receita Federal e do Banco do Brasil, passando em seguida a ser emitido em todas as agências próprias dos Correios, ação que ampliou o alcance do serviço para a totalidade dos municípios do país. É relevante ressaltar que além de atender aos serviços de emissão, regularização e pedidos de segunda via do CPF, a empresa também realiza a entrega domiciliar do documento, assegurando o seu acesso universal.

Os Correios também emitem certificados digitais no Brasil. A certificação digital é um documento que autoriza transações em ambiente virtual que demandam identificação clara do usuário, como o comércio eletrônico, a assinatura de contratos, governo eletrônico e algumas operações bancárias. Uma vez que esses documentos funcionam como identidade virtual, sua emissão somente é realizada por órgãos de autoridade certificadora ou uma autoridade de registro por ela

\footnotetext{
${ }^{1}$ Entrevista realizada no Museu dos Correios, Brasília-DF, em março de 2016.
} 
designada. No Brasil, os Correios são uma autoridade de registro para a criação de certificados digitais dos tipos e-CPF (pessoa física) e e-CNPJ (pessoa jurídica) em todo o território nacional ${ }^{2}$.

Os Correios também participaram ativamente no Programa Fome Zero, iniciado pelo governo do Presidente Lula (2003-2010) no ano de 2003. Durante a sua execução, as agências postais de todas as cidades foram os postos de arrecadação e entrega de mais de 615 toneladas de alimentos $^{3}$, cuja logística de distribuição também era realizada pela empresa desde a escala nacional até a escala local. Como o programa visava atingir os lugares e a população mais pobres do país, nenhum outro operador logístico dispunha de tamanha capilaridade e de uma infraestrutura montada que permitisse, com prontidão, atender aos objetivos estabelecidos.

A promulgação das resoluções normativas 2640 (de agosto de 1999) e 2707 (de maio de 2000) do Banco Central, instituindo a figura do "correspondente bancário" no cenário nacional foi o marco inicial que permitiu, a partir de então, a criação da marca Banco Postal ${ }^{4}$, autorizando aos bancos utilizarem as agências dos Correios na prestação de serviços bancários básicos à população. Segundo Dias (2009, p.12), o correspondente bancário é uma espécie de "objeto híbrido que combina serviço, tecnologia de comunicação e produto, e que viabiliza uma expansão territorial e social sem precedentes das redes bancárias no território brasileiro" (grifos da autora). Se de um lado essa medida foi de suma importância para levar os serviços bancários àqueles pontos do território que não eram atraentes para a abertura de agências tradicionais, por outro contribuiu para a ampliação do lucro dos bancos. Nos dez primeiros anos (2002-2011), o banco privado nacional Bradesco compôs a parceria com os Correios, levando o banco, na época, a utilizar-se da propaganda de presença em todo o território nacional. É um discurso do território, mas também uma ação no território, imprescindíveis para o sucesso do capitalismo na contemporaneidade, aliado inclusive às normatizações e instituições do Estado, como no exemplo em tela. Desde 2012, todavia, o Banco do Brasil substituiu o Bradesco na segunda fase do Banco Postal, desta vez duas instituições públicas dão seguimento ao projeto de Estado de levar os serviços bancários básicos a todos os municípios do país ${ }^{5}$.

O Brasil assistiu, portanto, a uma transformação qualitativa dos Correios em um correspondente bancário. Mas por que os Correios? Novamente, essas ações estão amparadas no caráter geograficamente difuso dos fixos postais, sobretudo as agências próprias dos Correios. A capilaridade é a característica que distingue a empresa de qualquer outra instituição pública ou privada no Brasil, mesmo se comparada aos maiores bancos (que já possuem um grande número de agências), a única que poderia levar a cabo essa iniciativa do Estado num prazo imediato, com tamanho êxito. Somado a essa característica, Contel (2006, p.251) atentou para o fato de que "sendo as agências dos Correios especializadas na circulação de informações, podem ser consi-

\footnotetext{
2 Para mais informações sobre os certificados digitais, consultar: https://www.correios.com.br/paravoce/compra/certificados-digitais.

${ }^{3}$ Conforme dados de Correios (2016).

${ }^{4}$ No mundo, o oferecimento de serviços bancários e financeiros por agências de correio não é novidade: surge na Inglaterra há mais de 100 anos e hoje pode ser encontrado em países como o Japão, França e Alemanha, sendo sua criação estimulada pela Organização das Nações Unidas e pelo Banco Mundial (CORREIOS, 2016).

${ }^{5}$ Para a surpresa de todos, inclusive do próprio Banco Bradesco que lograva a renovação do contrato, o Banco do Brasil venceu o leilão com o lance no valor de $\mathrm{R} \$ 2,3$ bilhões, expandindo virtualmente sua presença de pouco mais de 3000 para a quase totalidade dos municípios brasileiros. Qual seria o interesse do Estado, duplamente, em garantir a expansão de um banco público por meio de uma outra empresa pública? Podemos afirmar que o diferencial do Banco do Brasil nesta segunda fase (já que a mesma instituição participou do primeiro edital) reside na estratégia de um governo diferente daquele de 2001 , que havia realizado as privatizações anteriores?
} 
deradas como um circuito geográfico privilegiado para a instalação de uma rede de prestação de serviços bancários". Ao invés de construir agências ou criar outras estratégias, uma parceria entre o setor bancário e os Correios permitiu, quase que instantaneamente, levar os serviços aos municípios não atendidos. O estudo empreendido por Medeiros (2013) no estado de Alagoas revelou que a totalidade das agências dos Correios operam como correspondente bancário, elevando sobremaneira a presença do Banco do Brasil no território. Como toda ação sob o capitalismo guarda a sua propriedade de ser contraditória, não existe somente o interesse do Estado em expandir os serviços bancários à população. Os interesses de mercado das instituições bancárias, principalmente face à impelente concorrência a que foram expostas com a entrada de grandes conglomerados financeiros no país, atuaram juntamente com os objetivos estatais para melhorar o acesso e, consequentemente, a qualidade de vida da população antes marginalizada dos serviços bancários.

Também em parceria com o Banco do Brasil, os Correios executam desde 2003 o programa Exporta Fácil, por meio do qual é possível realizar exportação de remessas de até 30 quilogramas de qualquer lugar do país para todo o mundo. Com esse serviço, as agências dos Correios se transformam em recintos alfandegários ${ }^{6}$ da Receita Federal, com todo o desembaraço aduaneiro realizado no próprio local. O serviço está disponível para pessoa física ou jurídica, beneficiando principalmente microempresas, cooperativas e autônomos.

Os Correios também funcionam como uma espécie de operador logístico para o sistema judiciário brasileiro. Todos os documentos trocados entre os cartórios civis, comarcas, fóruns e tribunais seguem via postal, aumentando significativamente a demanda pelo serviço de carta registrada. Além disso, diante de qualquer julgamento no Brasil, somente o Aviso de Recebimento dos Correios é considerado como comprovação válida de troca de mensagens entre os sujeitos de direito, incluindo pessoas físicas e jurídicas.

No Brasil, a votação para eleições em todas as instâncias - municipal, estadual e federal passou a ser realizada eletronicamente desde o ano 1996. A automatização com o uso da urna eletrônica permitiu que a votação se realizasse ao mesmo tempo em todo o país, e ainda agilizou a divulgação do resultado para apenas alguns minutos ou horas a partir do encerramento do trâmite. Mas como as urnas chegam, em sigilo e segurança, a todos os lugares ao mesmo tempo? Próximo às eleições, uma grande operação logística mobilizada entre o Tribunal Superior Eleitoral e os Correios faz com que a votação eletrônica brasileira seja possível por meio da coordenação, amplamente sigilosa e veloz, da distribuição dos equipamentos aos locais de votação. É válido ressaltar que também os demais materiais, como formulários, placas identificadoras e todos os materiais necessários para o dia da votação também são entregues pelo serviço postal.

Desde 2011, os Correios passaram a executar em parceria com o Fundo Nacional de Desenvolvimento da Educação (FNDE) a maior operação de distribuição de livros didáticos do mundo. Integrando a Programa Nacional do Livro Didático (PNLD), a empresa distribui anualmente cerca de 137 milhões de livros e dicionários às mais de 140 mil escolas públicas brasileiras, totalizando 74 mil toneladas de material ${ }^{7}$. Essa operação logística é bastante peculiar, pois deve realizar a entrega do material didático às unidades de ensino a tempo do início do ano letivo e em

\footnotetext{
${ }^{6}$ Os Correios se diferenciam dos portos secos e os Centros Logísticos e Industriais Aduaneiros, estudados por Penha (2010), pois estes são utilizados principalmente, como o autor indica, pelas grandes empresas.

${ }^{7}$ Segundo informações disponibilizadas em Correios (2016).
} 
quantidade adequada conforme as matrículas realizadas para aquele período. Essa ação permite, na prática, que haja a unificação do sistema de ensino nacional sob uma base curricular comum e a superação da escassez de produção de material didático, especialmente para os lugares mais remotos.

Também em parceria com o Ministério da Educação (MEC), os Correios são o elo material que permite a realização dos exames nacionais de educação. Como aplicar provas como o Exame Nacional do Ensino Médio (ENEM), o Exame Nacional de Desempenho de Estudantes (ENADE), a Provinha Brasil, entre outros, em todos os municípios brasileiros simultaneamente? Durante o ENEM, as agências postais se transformam em locais oficias de inscrições, que somente em 2013 totalizou 7 milhões. A logística dos Correios realiza a entrega sigilosa das provas em todos os locais de aplicação cerca de uma hora antes do início do certame, e realiza a coleta após o encerramento das atividades, no mesmo dia. Em 2013 foram 47 mil malotes de ida e volta entregues em mais de 11 mil destinos no país. Desta maneira, o MEC garante o sigilo das provas e utiliza a rede postal como uma maneira eficiente e barata de realizar o exame em escala nacional. O mesmo ocorre no caso de concursos públicos: as parcerias entre os Correios e as instituições aplicadoras de exames é o que permite a concretização das ações coordenadas, com serviço completo de logística antes, durante e após a aplicação das provas.

No âmbito das políticas nacionais de saúde, os Correios participam da distribuição de vários materiais, desde cartazes das campanhas do Ministério da Saúde aos postos e hospitais até pequenos equipamentos, materiais cirúrgicos, etc. Na complexa etapa da distribuição do circuito espacial produtivo da vacina, muitas delas só conseguem chegar às pequenas cidades, vilas e povoados por meio de um transporte especial providenciado pelos Correios.

Em casos de catástrofes "naturais" no país, como enchentes, secas, deslizamento de terra em bairros de encosta, incêndios, tornados, entre outros, os Correios são acionados para operações sazonais de distribuição de donativos. Nessas circunstâncias, as agências passam a funcionar temporariamente como postos de arrecadação de alimentos, roupas, medicamentos, brinquedos, etc. de onde são encaminhados para o local atingido para serem entregues pela agência postal local.

Esses são os casos mais destacados em escala nacional. Regional e localmente, outras instâncias estatais também realizam ações de políticas públicas que dependem estritamente dos serviços postais e sua rede de fixos geográficos. Em parceria com os Correios, a Prefeitura Municipal de São Paulo entrega mensalmente 1.700 toneladas de leite em cerca de 350 mil domicílios cadastrados, operação que mobiliza com exclusividade 190 empregados em 156 veículos dos Correios, perfazendo 3.120 diferentes rotas de distribuição na cidade.

\section{Serviço postal e cidadania}

Elaborar uma reflexão e uma interpretação do correio brasileiro considerando sua complexidade e as múltiplas funções que desempenha na atualidade reclama o tratamento do tema da cidadania. Para Milton Santos, a realização concreta da cidadania somente se torna possível com a componente territorial. Para tanto, propõe um modelo cívico do território em substituição ao modelo eco- 
nômico vigente, que se funda a partir de dois elementos - a cultura e o território. Para o autor, fazse necessário

de um lado, uma instrumentação do território capaz de atribuir a todos os habitantes aqueles bens e serviços indispensáveis, não importa onde esteja a pessoa; e, de outro lado, uma adequada gestão do território, pela qual a distribuição geral dos bens e serviços públicos seja assegurada (SANTOS, [1987] 2007, p.18)

Nesse modelo, o território seria pensado visando uma política redistributiva, de maneira a permitir o acesso aos serviços fundamentais independentemente do lugar onde se esteja. Essas ações seriam fundamentais para garantir uma cidadania completa, com a satisfação das necessidades mais básicas e essenciais no lugar onde a população habita. Para isso, é necessária uma mudança no uso e na gestão do território que oriente para lógicas que extrapolem a busca pelo lucro. Essa proposta sob um novo paradigma de organização e planejamento do território deve ser entendida como um direito inalienável do cidadão, já que deixar ao mercado a prestação de serviços básicos à vida contribui para o acirramento das desigualdades e a seletividade de acesso.

Em sua proposta, Santos ([1987] 2007) elabora uma distinção entre os "fixos públicos" e os "fixos privados". Os fixos privados seriam aquelas infraestruturas construídas e controladas pelo mercado, cuja distribuição no território obedece à lógica da máxima lucratividade. Já no caso dos fixos públicos, sob o controle do Estado, a lógica de sua implantação difere do mercado e acompanha - ou deveria acompanhar - o suprimento das necessidades da população. Nesse sentido, os fixos públicos podem também ser considerados como "fixos sociais". A instalação de novos fixos sociais nos lugares contribuiria, assim, para alterar as condições de vida da população.

Compreendendo o serviço postal brasileiro como um serviço público, haveria correspondência entre a topologia dos Correios e o modelo cívico do território? Ao propor uma política orientada para a criação de fixos sociais, Santos ([1987] 2007, p.59) assegura que "no caso das cidades, bastaria um projeto consequente para dotar a população de 'fixos' sociais. E no interior, a necessidade é de criar, 'artificialmente', núcleos destinados a servir às populações em derredor, ou fortalecer aglomerações já existentes...". Ao instalar agências em todas as cidades brasileiras e, além disso, ainda criar unidades de atendimento em vilas e áreas rurais mesmo quando os lucros da unidade não cobrem as despesas de seu funcionamento, ao garantir a entrega domiciliar em todos os escalões da rede urbana - da metrópole às cidades ribeirinhas da Amazônia - assegurando um serviço postal universal, os Correios se aproximam da noção de um modelo cívico, cujos fixos postais cumprem, em muitos casos, funções de fixos sociais.

Embora associada aos interesses de mercado na atual fase da globalização, a logística nasceu no seio do Estado e deve ser problematizada como uma ação estratégica para a execução de políticas públicas. A logística postal, por seus atributos espaciais (espaço banal) e temporais (cotidiano), além da própria natureza do objeto postal e a diversidade dos agentes envolvidos, não pode ser assumida pelo mercado, dada a própria limitação do escopo de ação dos agentes privados. Ela se revela estreitamente a fim a um modelo mais igualitário de distribuição de bens e serviços básicos à população, se se compreende o correio como parte da infraestrutura do território (GERTEL, 1991) e não apenas como um serviço complementar - o correio, mais que um operador logístico postal, é um elemento imanente do território. 
Por sua importância histórica na formação socioespacial brasileira, o correio é um importante elo de integração territorial, não somente nas extintas administrações postais, mas sobretudo hoje. Essa atribuição geoestratégica do Estado encontra na instituição postal uma característica peculiar que possibilita articular todos os domicílios sob uma mesma lógica. Como relegar ao mercado tamanha atribuição? Certamente não é possível avançar em direção a um modelo cívico ao reduzir a integração do território à imagem da topologia seletiva das corporações postais privadas. O correio brasileiro, com toda a sua complexidade, nos deixa pistas para entender a construção desse projeto de futuro.

Desse modo, ratifica-se a importância de manter um serviço postal público no Brasil, especialmente pelas características que possui. Os fluxos majoritariamente regionais de correspondências desmistificam a ideia de um fluxo global e recoloca a questão nacional na ordem do dia: quem pode assumir os serviços na Amazônia ou no interior da região Nordeste, senão o Estado? A constatação de que mesmo no interior do país os fluxos postais inter-regionais (longa distância) são minoritários se comparados às trocas dentro de uma mesma região também relativiza a noção de um correio a serviço das empresas do circuito superior, cuja concentração na metrópole paulista dá uma dimensão da divisão territorial do trabalho, mas está longe de traduzir a complexidade do correio como um fenômeno multiescalar. Nesse sentido, a diversidade de agentes que utilizam o serviço postal desloca o debate do âmbito corporativo, que se alimenta dos interesses dos grandes postadores (e-commerce, mídia impressa, bancos e operadoras de títulos de pagamento, etc.) em fazer do correio a imagem de seus interesses, para alcançar na esfera pública o lugar de sua realização, permitindo a satisfação de todos os agentes independentemente de sua localização no território.

Assim, a construção de um modelo cívico excede a vorticidade (leia-se: vorti-cidade) dos serviços mais expressos (como os seletivos SEDEX 10, SEDEX Hoje, etc.) para incluir as múltiplas temporalidades dos lugares, de todos eles. Por isso deve-se insistir no fato de que as empresas postais privadas, ao priorizarem os serviços expressos, estão aquém de um modelo de consolidação da cidadania.

Deve-se compreender a velocidade em sua dimensão política, juntamente com a técnica. Para que e para quem a rapidez ou a lentidão? Onde elas têm lugar? Na construção de um modelo cívico, importará mais o tempo das necessidades da população e dos lugares do que o tempo mais expresso, produtor de alienação.

\section{De lugares para a logística a uma logística para os lugares}

Esse conjunto da materialidade e das ações dos Correios aponta para um modelo cívico do território, pautado na mais igualitária distribuição e na maior acessibilidade possível aos serviços públicos de qualidade, indispensáveis à consolidação da cidadania. Destarte, torna-se indispensável um planejamento territorial assumido pelo Estado, que crie condições materiais e normativas para impulsionar uma logística a favor dos lugares, com vistas a suprir as necessidades cotidianas de populações inteiras marginalizadas pelo mercado.

A logística deve ser problematizada enquanto uma atividade que, deixada exclusivamente ao mercado, mais se beneficia dos lugares e de suas virtualidades do que os favorece. Calcada 
no lucro, a logística empresarial é um modelo eficiente de drenagem dos recursos disponíveis nos lugares para os centros de gravidade da economia capitalista. O atual modelo que se impõe é aquele dos lugares para esse tipo de logística, onde as diferentes porções do território adequam suas infraestruturas, seu conteúdo técnico e normativo, e se rearranjam para permitir que a logística, espécie de Hermes contemporâneo, o deus da velocidade, possa reinar, especialmente para alguns. Urge pensar num outro modelo possível, aquele de uma logística para todos os lugares, onde estes tenham as suas necessidades básicas supridas e favorecidas pelos progressos técnicos da humanidade.

Juntamente com a geógrafa Bertha Becker (2007), reiteramos a necessidade de pensar uma "logística do pequeno", ou ainda uma logística do Estado para o pequeno, aquela que favoreça também os esquecidos pelo mercado e pelas lógicas empresariais que se beneficiam das infraestruturas e dos valores socialmente produzidos. Nos Correios, além das mencionadas políticas públicas, a permanência de um serviço como a "carta social"8 aponta nessa direção. É mister assegurar o acesso aos serviços mais básicos e às redes de todos os tipos por parte das pequenas empresas, das pequenas cidades, das regiões mais remotas, das pessoas mais pobres - não porque podem pagar pelos custos dos serviços e se configuram enquanto potencial mercado consumidor, mas como um direito, devidamente assegurado pelo Estado aos cidadãos.

Para o planejamento territorial há um desafio que se coloca: é possível estabelecer uma logística para os lugares, que favoreça o suprimento das necessidades locais e atenda às demandas da população? No caso da logística empresarial, o uso corporativo do território produz antes lugares para a logística do que uma logística para os lugares. Algumas ações dos Correios, especialmente aquelas vinculadas à execução de políticas públicas, apontam para uma logística que pode contribuir na constituição de solidariedades entre os lugares.

\section{Considerações finais}

Um serviço público de correio, tal qual o adotado no Brasil, coloca como central a questão do uso do território. No bojo das tensões entre Estado e mercado, além da circulação das coisas está em jogo a integração territorial, a conexão dos lugares e a constituição de um elo de articulação material entre as empresas, instituições e a população em geral. Desta maneira, o território manifesta as consequências desse conflito, como mediação e condição essencial para a realização das ações concretas desses agentes na sociedade. A problemática levantada por Mattelart (1994, p.16) duas décadas atrás continua a ecoar e desafiar as investigações por uma resposta atual: "Entre Estado e setor privado, quem deve controlar a circulação da informação, a implantação e o funcionamento das redes de comunicação à distância? Quem está autorizado a utilizar os novos serviços?".

A universalidade do serviço de correio, a distribuição dos fixos postais, os fluxos regionais de correspondências, as funções desempenhadas pelos Correios (não somente postal, mas de

\footnotetext{
${ }^{8}$ Serviço de envio de cartas com valor simbólico de $\mathrm{R} \$ 0,01$ (um centavo). Para o seu envio, devem ser cumpridos os seguintes requisitos: carta manuscrita; remetente e destinatário sejam pessoas físicas; peso de até $10 \mathrm{~g}$; envio máximo de cinco unidades por remessa.
} 
serviços financeiros, comerciais e de logística de Estado), sua relevância histórica para o país, sua importância econômica, política e social convidam para uma imperiosa defesa de seu caráter público, em favor da continuidade de suas ações em benefício de pessoas e lugares localizados nas periferias do Brasil. Esta também pode ser entendida como uma tentativa de atualização, sobretudo em termos geográficos, do debate em torno do projeto neoliberal de privatização dos Correios no Brasil.

Os resultados apresentados convidam a um debate atual sobre o correio brasileiro considerando sua dimensão territorial, na encruzilhada entre os interesses externos e as necessidades internas do país. Amparadas em anseios geopolíticos e geoeconômicos, as empresas multinacionais de correio (FedEx, UPS e DHL, principalmente) reproduzem a perversa ordem mundial vigente, que favorece exclusivamente os capitais concentrados nos países centrais e que busca, agora, o controle sobre os fluxos das cartas e encomendas de todo o mundo.

Aprovado pela Comissão Científica do III CONGEO - Congresso Brasileiro de Geografia Política, Geopolítica e Gestão do Território

Universidade Federal Fluminense - Niterói (RJ), 2018 
Referências

ARROYO, Mónica. Território, mercado e estado: uma convergência histórica. Geographia (UFF), Niterói, v.12, p.49-66, 2004.

BECKER, Bertha. Logística e nova configuração do território brasileiro: que geopolítica será possível? In: DINIZ, C. C. (org.). Políticas de desenvolvimento regional: desafios e perspectivas à luz das experiências da União Europeia e do Brasil. Brasília: Editora da Universidade de Brasília, 2007.

. A geopolítica na virada do milênio: logística e desenvolvimento sustentável. In: CASTRO, Iná Elias; GOMES, Paulo C. da Costa; CORRÊA, Roberto Lobato (orgs.). Geografia: conceitos e temas. 13ed. Rio de Janeiro: Bertrand Brasil, 2010, pp.271-307.

CASTILLO, Ricardo. Agricultura globalizada e logística nos cerrados brasileiros. In: SILVEIRA, Márcio Rogério (org.). Circulação, transporte e logística: diferentes perspectivas. São Paulo: Outras Expressões, 2011, pp.331-354.

CONTEL, Fábio Betioli. Território e finanças: técnicas, normas e topologias bancárias no Brasil. 2006. 343 f. Tese (Doutorado em Geografia Humana) - Faculdade de Filosofia, Letras e Ciências Humanas, Universidade de São Paulo, São Paulo, 2006.

CORREAA, Roberto Lobato. Estudos sobre a rede urbana. Rio de Janeiro: Bertrand Brasil, 2006.

CORREIOS. História postal. Disponível em <http://www.correios.com.br/sobre-correios/aempresa/historia>. Acesso em: 21 ago. 2018.

DIAS, Leila. Finanças, política e território. Caderno CRH (UFBA), v.22, n.55, p.9-13, 2009.

GERTEL, Sérgio. Geografia, informação e comunicação: a imagem postal brasileira. 1991. 274 f. Dissertação (Mestrado em Geografia Humana). Departamento de Geografia, Faculdade de Filosofia, Letras e Ciências Humanas, Universidade de São Paulo, São Paulo, 1991.

GOTTMANN, Jean. (1975) A evolução do conceito de território. In: Boletim Campineiro de Geografia, v.2, n.3, p.523-545, 2012.

MATTELART, Armand. Comunicação-mundo: história das ideias e das estratégias. Trad. Guilherme J. F. Teixeira. 2 ed. Petrópolis: Vozes, 1994.

MEDEIROS, Dhiego. Financeirização do território e circuitos da economia urbana: agentes de crédito, técnicas e normas bancárias. Um exemplo em Alagoas. 2013. 275 f. Dissertação (Mestrado em Geografia Humana) - Faculdade de Filosofia, Letras e Ciências Humanas, Universidade de São Paulo, São Paulo, 2013.

PEREIRA, Evelyn. A empresa e o lugar na globalização: a "responsabilidade social empresarial" no território brasileiro. 2007. 205 f. Dissertação (Mestrado em Geografia Humana) — Faculdade de Filosofia, Letras e Ciências Humanas, Universidade de São Paulo, São Paulo, 2007.

RAFFESTIN, Claude. Por uma geografia do poder. São Paulo: Ática, 1993. 
SANTOS, Milton. (1987) O espaço do cidadão. 7 ed. São Paulo: Edusp, 2007.

. (1996) A natureza do espaço. Técnica e tempo. Razão e emoção. 4 ed. 7 reimpr. São Paulo: Edusp, 2012.

; SILVEIRA, María Laura. (2001) O Brasil: território e sociedade no início do século XXI. 15 ed. Rio de Janeiro: Record, 2011.

VENCESLAU, Igor. Correios, logística e uso do território: o serviço de encomenda expressa no Brasil. 2017. 250 f. Dissertação (Mestrado em Geografia Humana). Faculdade de Filosofia, Letras e Ciências Humanas, Universidade de São Paulo, São Paulo, 2017. 